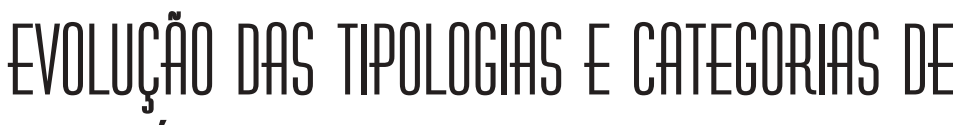 ÁREAS PROTECLIDAS NO BAAFSL"
}

\section{RODRIGO MEDEIROS **}

\section{INTRODUÇÃO}

As áreas protegidas são espaços territorialmente demarcados cuja principal função é a conservação e/ou a preservação de recursos, naturais e/ou culturais, a elas associados (MEDEIROS, 2003). Segundo a União Mundial para a Conservação da Natureza (UICN), elas podem ser definidas como "uma área terrestre e/ou marinha especialmente dedicada à proteção e manutenção da diversidade biológica e dos recursos naturais e culturais associados, manejados através de instrumentos legais ou outros instrumentos efetivos" (UICN, 1994:7).

Sua criação pode ser considerada importante estratégia de controle do território já que estabelece limites e dinâmicas de uso e ocupação específicos. Este controle e os critérios de uso que normalmente a elas se aplicam são freqüentemente atribuídos em razão da valorização dos recursos naturais nelas existentes ou, ainda, pela necessidade de resguardar biomas, ecossistemas e espécies raras ou ameaçadas de extinção.

Equivocadamente reduzidas com freqüência à terminologia "unidades de conservação", uma das tipologias previstas atualmente no modelo brasileiro, as áreas protegidas no Brasil encerram um grupo muito mais abrangente de tipologias e categorias, cuja discussão e práxis de criação atravessaram todo o período republicano brasileiro (MEDEIROS, 2004; MEDEIROS et al, 2004).

\footnotetext{
" Este trabalho reúne resultados de minha tese de doutorado no Depto. de Geografia da UFRJ (MEDEIROS, 2003) e das pesquisas desenvolvidas durante o pós-doutoramento no Depto de Ecologia e Gestão da Biodiversidade do Museu Nacional de História Natural de Paris. Agradeço a Irene Garay e Bertha Becker pelos momentos de profícua discussão destes resultados e a Capes pelo auxílio financeiro. Agradeço também as valiosas contribuições dadas pelos dois revisores anônimos da revista.

** Doutor em Geografia; Pós-Doutor em Gestão da Biodiversidade. Professor Adjunto do Dept de Ciências Ambientais/ Instituto de Florestas da UFRRJ. Pesquisador Associado do Laboratório de Gestão da Biodiversidade do Instituto de Biologia da UFRJ

E-mail: medeiros@biologia.ufrj.br

Recebido em 08/2005 - Aceito em 12/2005
} 
A proliferação desses instrumentos - fruto em certa medida da ampliação da percepção social sobre a necessidade de criação de regimes especiais de proteção dos recursos naturais - teve como uma das conseqüências a criação de um sistema pouco articulado e redundante. Este problema, de solução complexa, foi parcialmente equacionado, como discutiremos neste trabalho, com a instituição do Sistema Nacional de Unidades de Conservação da Natureza (SNUC) em 2000.

De maneira geral, a criação de um instrumento de proteção e, por conseqüência, de novas tipologias de áreas protegidas, reflete, precisamente, tanto as expectativas sociais de grupos interessados, quanto os arranjos políticos e institucionais que exercem pressão ou influência sobre o Estado. Uma análise feita sobre a evolução destes instrumentos é, portanto, importante indicador da lógica política e social de criação de áreas protegidas no país e pode nos auxiliar, sobremaneira, a compreender a organização e os objetivos do sistema atual.

Este trabalho tem por objetivo apresentar e analisar criticamente a evolução dos instrumentos e tipologias de áreas protegidas instituídas no Brasil, buscando revelar intenções e contradições deste processo, bem como suas conseqüências e influência sobre o modelo atual, fortemente centrado no Sistema Nacional de Unidades de Conservação. Para tal, utilizou-se como fonte principal a pesquisa bibliográfica sobre o tema e a análise documental dos diferentes instrumentos políticos e legais instituídos no Brasil. Os dados quantitativos sobre as áreas protegidas por tipologia foram obtidos a partir de diferentes fontes - Ministério do Meio Ambiente, IBAMA, OEMAs, ONGs - tendo em vista a inexistência de um sistema nacional que organize e disponibilize essas informações. A análise e discussão apresentadas a seguir foram feitas a partir de um recorte temporal que buscou evidenciar as principais características e conseqüências das ações de proteção empreendidas no país. É pertinente, ainda, justificar aqui que a intenção perseguida ao propor uma periodização deste processo não é a análise histórica, mas sim as marcas por ele deixadas. Dessa forma, o trabalho está organizado em três seções. Na primeira, são apresentados os antecedentes e debates que levaram à criação das primeiras áreas protegidas brasileiras, indicando seus contextos sociopolíticos. $\mathrm{Na}$ segunda, discute-se de que maneira procedeu a evolução das principais tipologias e categorias de áreas protegidas instituídas no país. Finalmente, na terceira seção, à guisa de conclusão, é apresentada uma reflexão geral sobre esse processo, assim como a excessiva centralização do modelo brasileiro na tipologia "Unidade de Conservação".

\section{A GÊNESE DAS PRIMEIRAS ÁREAS PROTEGIDAS NO BRASIL}

Tem sido consenso entre muitos autores apontar o Parque Nacional de Itatiaia, criado em 1937 no Rio de Janeiro, como a primeira área protegida do Brasil (DIEGUES, 2001; FERREIRA, 2004; CABRAL; 2002). De fato, este Parque representou a materialização de longos anos de debates e mobilizações iniciados ainda durante o período colonial e imperial, mas que efetivamente não se traduziram em ações concretas pelo governo federal até este ano (MEDEIROS, 2003) 
$\bigcirc$ Brasil foi um dos países que mais tardiamente sucumbiu à onda internacional de criação de Parques, após a iniciativa americana de 1872. No entanto, os registros históricos indicam que tanto a coroa portuguesa quanto o governo Imperial empreenderam algumas iniciativas destinadas à proteção, à gestão ou ao controle de determinados recursos naturais.

Os primeiros dispositivos voltados à proteção de áreas ou recursos em terras brasileiras têm seu registro ainda no período colonial. $\bigcirc$ principal objetivo era a garantia do controle sobre o manejo de determinados recursos, como a madeira ou a água, tal e qual já se praticava em algumas partes da Europa. Desde o século XV, vários Estados europeus intervinham diretamente na proteção, no controle e no acesso de recursos naturais como, por exemplo, a madeira, esta última representando um importante recurso militar (construção de embarcações) e econômico (construção de residências e combustível para aquecer os palácios e castelos da nobreza). É o caso das ordenações reais francesas de Jean Colbert, durante o reinado de Luis XIV, e das ordenações portuguesas de D. Manuel I, conhecidas como "manuelinas", que incluíam vários dispositivos de proteção das florestas e dos recursos hídricos que, mais tarde, foram também aplicados no Brasil (CASTRO, 2002; LARRÈRE \& LARRÈRE, 1999; MEDEIROS, 2003; MIRANDA, 2004; ONF, 2003).

Dois exemplos emblemáticos dessa prática em terras brasileiras são o "Regimento do Pau-Brasil" editado em 1605 e Carta Régia de 13 de março de 1797 (CARVALHO, 1967; MIRANDA, 2004). O primeiro, que pode ser considerado uma das primeiras leis de proteção florestal brasileira, estabelecia rígidos limites à prática de exploração do pau-brasil na colônia:

"Primeiramente Hei por bem, e Mando, que nenhuma pessoa possa cortar, nem mandar cortar o dito pau brasil, por si, ou seus escravos ou Feitores seus, sem expressa licença, ou escrito do Provedor mór de Minha Fazenda, de cada uma das Capitanias, em cujo distrito estiver a mata, em que se houver de cortar; e o que o contrário fizer encorrerá em pena de morte e confiscação de toda sua fazenda" (MIRANDA, 2004:2)

Já a Carta Régia afirmava ser necessário tomar as precauções para a conservação das matas no Estado do Brasil, e evitar que elas se arruinassem ou fossem destruídas (CARVALHO, 1967). Este decreto real, dentre outras providências, visava coibir o corte não autorizado pela coroa de determinadas espécies de árvores cuja madeira, considerada nobre (cedro, mogno, entre outras), representava importante recurso para a metrópole.

Boa parte dessas medidas advinha dos diversos inventários realizados a serviço da coroa portuguesa visando determinar a existência de recursos naturais estratégicos que poderiam ser explorados e controlados. Entre os séculos XVII e XVIII, por exemplo, a Coroa Portuguesa ao empreender o levantamento dos recursos naturais na bacia do Amazonas e fechar sua navegação a embarcações estrangeiras, buscava reafirmar sua soberania sobre esta região, impondo uma política de severo controle e acesso a estes recursos (BECKER, 2000; 2001). 
Entretanto, todos os instrumentos adotados tanto pela metrópole portuguesa quanto, mais tarde, pelo Império, tinham seu foco de proteção essencialmente centrado em determinados recursos naturais sem necessariamente haver a demarcação de áreas ou territórios específicos - característica essa que confere sentido e significado ao termo "área protegida". Essa noção só começou a ser modificada e praticada, não apenas no Brasil, à medida que os efeitos oriundos dos impactos decorrentes da devastação de extensas áreas, seja pela exploração e corte da madeira, seja pelo empobrecimento dos solos, fizeram-se mais evidentes.

No Rio de Janeiro, a expansão dos plantios de café no século XVIII, por volta de 1760 , em direção à floresta da Tijuca, até então bem preservada, levou à derrubada da mata primitiva de praticamente toda a serra da carioca (Morros do Trapicheiro, Sumaré, Corcovado e Paineiras). Esta ação predatória causou a decadência dos cafezais, pelo rápido declínio da produtividade e a presença de pragas, já na primeira metade do século XIX. Então, já no Império, D. Pedro II voltou-se para a Floresta com o objetivo de captar água para a cidade. Porém, o processo de desmatamento havia comprometido seriamente os estoques hídricos da região. Visando recuperá-los e resguardá-los, o Imperador ordenou a sua imediata desapropriação (BARRETTO FILHO, 2004).

A desocupação dessas áreas pelo Governo Imperial começou em 1844, com a decisão inédita e histórica de replantar toda a vegetação local segundo recomendação de D. Pedro II. Em 1857, o Barão de Bom Retiro, Ministro dos Negócios do Império, iniciou a desapropriação das fazendas devastadas pelas plantações de café instituindo, em 1861, as "Florestas da Tijuca e das Paineiras", com o objetivo de resguardar os recursos hídricos da região (DRUMMOND, 1997; BARRETO-FILHO, 2004). É possível que, pelos registros disponíveis, elas efetivamente tenham sido as primeiras áreas protegidas do país, um esboço do que viriam mais tarde a ser as florestas protetoras instituídas pelo Código Florestal de 1934 (MEDEIROS, 2003).

É fato que, ainda durante o período Imperial, muitas foram as personalidades que se engajaram na criação de áreas protegidas no país. Os debates sobre a proteção de espécies ameaçadas de extinção e o esgotamento dos recursos que dominavam a cena no velho continente exerceram especial influência na emergente classe intelectual brasileira, em boa parte formada nas tradicionais escolas européias (DEAN, 2002). Dentre esses, um dos expoentes da chamada crítica ambiental brasileira foi, sem dúvida, José Bonifácio que, no início do século XIX, demonstrava forte motivação na defesa pela proteção dos recursos florestais. Ele tinha grande preocupação com a destruição das florestas, pois havia estudado os efeitos do desmatamento sobre a fertilidade dos solos em Portugal (PÁDUA, 2003). Em 1821, Bonifácio sugeriu a criação de um setor administrativo especialmente responsável pela conservação das florestas, uma vez que vastas porções da Mata Atlântica, sobretudo no Nordeste, tinham sido destruídas para utilização da madeira (CABRAL, 2002; DEAN, 2002).

Mas foi somente em 1876, por sugestão do engenheiro André Rebouças já inspirado na criação do Parque de Yellowstone nos Estados Unidos em 1872 - que houve a primeira iniciativa para a criação de um Parque Nacional no Brasil. A idéia 
original era a de criar dois Parques Nacionais: um em Sete Quedas e outro na Ilha do Bananal. Esta proposta, que acabou não se concretizando, abriu espaço para uma ampla discussão e mobilização nos anos seguintes, que contribuiu significativamente para a criação dos primeiros parques nacionais brasileiros (MEDEIROS et al, 2004).

Embora fossem expressivas as manifestações em prol da criação de parques no Brasil durante o segundo reinado, tais pretensões se efetivaram apenas após a proclamação da República. A pioneira criação do Parque Estadual de São Paulo, em 1896, foi um passo importante nesta direção (MEDEIROS et al, 2004).

Outro movimento importante, foi a concretização no Brasil, em 1911, do primeiro grande esforço em favor do já internacional movimento de criação de áreas naturais protegidas: a publicação do "Mapa Florestal do Brasil”. Esta obra, cujo responsável foi o cientista brasileiro Luís Felipe Gonzaga de Campos, é o primeiro estudo abrangente feito em nosso país com uma descrição detalhada dos diferentes biomas e seus estados de conservação. Ele tinha a expressa intenção de subsidiar as autoridades brasileiras para a criação de um conjunto de Parques Nacionais. Tal como vinha ocorrendo em outros países, ele tinha como finalidade a conservação da beleza natural e de bons exemplos da natureza ainda intacta, antes de sua destruição pelo desenvolvimento humano, segundo os preceitos estabelecidos pela ideologia norteamericana de preservação da wilderness (COSTA, 2003).

Em decorrência de sua publicação, decretos foram editados na mesma época pela Presidência da República, criando dois Parques Nacionais no então território do Acre. A iniciativa foi tão avançada para o início do século no país, que os decretos caíram no total esquecimento e essas áreas nunca foram implementadas. Apenas recentemente, em meados dos anos 90, descobriram-se esses instrumentos legais e constatou-se que os nossos primeiros parques nacionais já estavam quase completamente destruídos, não havendo mais sentido procurar preservá-los. Somente parte que se salvou de um deles está hoje inserida dentro da Estação Ecológica do Rio Acre (COSTA, 2003).

A fragilidade dos instrumentos e das instituições da recém-estabelecida República brasileira, ainda dominada pelas elites rurais, não eram suficientes para garantir a manutenção de tão ambicioso projeto de criação de áreas com regimes especiais de proteção em função dos seus recursos naturais. Foram necessários que mais de 20 anos se passassem até que um instrumento robusto fosse enfim editado e, finalmente, criasse plenas condições para garantir a existência do primeiro Parque Nacional brasileiro em 1937.

\section{EVOLUÇÃO DOS INSTRUMENTOS POLÍTICOS E TIPOLOGIAS DE ÂREAS PROTEGIDAS NO BRASIL REPUBLICANO}

No quadro 1, apresenta-se uma síntese dos principais instrumentos instituídos no Brasil durante a República, voltados para a criação de áreas protegidas. Eles estão agrupados por período e com a indicação de suas principais características. A periodização adotada utilizou como critério a criação de instrumentos legais que 
modificaram ou contribuíram significativamente para alterar a estrutura e a lógica de criação de áreas protegidas vigentes até então. Dessa forma, o ano que marca o início de um novo período é o mesmo em que este instrumento foi criado. Assim, a instituição do Código Florestal, em 1934, estabelece o marco inicial deste período, tal como o Novo Código Florestal de 1965 e o SNUC em 2000, estabelecem, respectivamente, o início dos períodos subseqüentes. Cada um desses períodos será analisado e discutido a seguir.

\section{A/ De 1934 a 1964}

O início da década de 30 é marcado por importantes mudanças no cenário político e social brasileiro pois, com a Revolução de 30, inicia-se o processo de transição de um país até então dominado pelas elites rurais para outro que começa a se industrializar e urbanizar, principalmente na região sudeste (CUNHA \& COELHO, 2003). No curto espaço de tempo entre os anos de 1934 e 1937, grande parte dos instrumentos legais que dariam o suporte necessário para a efetiva criação de áreas protegidas no Brasil foi estabelecida, em contraposição ao imobilismo quase que total com que esta questão vinha sendo tratada pelo governo central desde a instituição da República em 1889.

Diversos fatores convergiram para a criação de um ambiente político e institucional favorável a tais mudanças. Em parte, a influência e pressão de movimentos organizados voltados à proteção da natureza, que aqui começavam a melhor se aparelhar, aliadas à necessidade de reorganização da exploração florestal no Brasil, estabeleceram importantes referenciais para a construção de uma nova política ambiental.

Somado a esses, um outro fator também preponderante foi a construção de novo projeto político para o país, que tinha na modernização e na busca de maior inserção internacional seu principal norte. A partir dos anos 30, com a ascensão de Getúlio Vargas à Presidência da República, mudanças políticas foram implementadas visando colocar o Brasil no trilho rumo à modernidade. Novas leis trabalhistas, incentivos à industrialização e à expansão e ocupação do oeste brasileiro ditaram o ritmo das mudanças. Neste cenário de ambiciosas transformações, o "ambientalismo" brasileiro que pregava a criação de áreas protegidas sob a forma de parques nacionais - a esta altura uma tendência internacional - encontrou enfim espaço (BECKER, 1999; MEDEIROS, 2005).

A consolidação das aspirações conservacionistas ficou registrada na segunda constituição republicana brasileira, de 1934. Nela, pela primeira vez, a proteção da natureza figurava como um princípio fundamental para o qual deveriam concorrer a União e os Estados. Em seu texto (Capítulo I, artigo 10), ficou definida como responsabilidade da União "proteger belezas naturais e monumentos de valor histórico e artístico". 
QUADRO 1: Evolução dos principais instrumentos de criação de Áreas Protegidas no Brasil

\begin{tabular}{|c|c|c|c|c|}
\hline PERÍODO & INSTRUMENTOS & $\begin{array}{l}\text { INSTRUMENTOS } \\
\text { INCORPORADOS }\end{array}$ & TIPOLOGIAS & CATEGORIAS \\
\hline \multirow{2}{*}{$\begin{array}{l}\text { De } 1934 \\
\text { até } 1964\end{array}$} & Código Florestal (Dec. 23793/1934) & & $\begin{array}{l}\text { Floresta Protetora; Floresta Remanes- } \\
\text { cente; Floresta de Rendimento; Flo- } \\
\text { resta Modelo }\end{array}$ & $\begin{array}{l}\text { Parque Nacional; Floresta Nacional; Reserva de } \\
\text { Proteção Biológica ou Estética }\end{array}$ \\
\hline & Código de Caça e Pesca (Dec. 23793/1934) & $-x-$ & $\begin{array}{l}\text { Parques de Criação e Refúgio de Ani- } \\
\text { mais }\end{array}$ & $\begin{array}{l}\text { Parque de Reserva, Refúgio e Criação de Animais } \\
\text { Silvestres }\end{array}$ \\
\hline \multirow{11}{*}{$\begin{array}{l}\text { De } 1965 \\
\text { até } 1999\end{array}$} & Novo Código Florestal (Lei 4771/1965) & $\begin{array}{l}\text { Código Florestal (Dec. 23793/ } \\
\text { 1934) }\end{array}$ & $\begin{array}{l}\text { ParqueNacional; Floresta Nacional; } \\
\text { Área de Preservação Permanente; } \\
\text { Reserva Legal }\end{array}$ & $-x-$ \\
\hline & $\begin{array}{l}\text { Lei de Proteção aos Animais (Lei } \\
\text { 5197/1967) }\end{array}$ & $\begin{array}{l}\text { Lei de Proteção aos Animais (Dec. } \\
\text { 24645/1934) }\end{array}$ & $\begin{array}{l}\text { Reserva Biológica; Parque de Caça } \\
\text { Federal }\end{array}$ & $-x-$ \\
\hline & $\begin{array}{l}\text { Programa MaB, } 1970 \text { (Dec. 74685/74 e Dec. } \\
\text { Pres. 21/09/99) }\end{array}$ & $-x-$ & \begin{tabular}{|l|}
$\begin{array}{l}\text { Áreas de Reconhecimento Interna- } \\
\text { cional }\end{array}$ \\
\end{tabular} & Reserva da Biosfera \\
\hline & $\begin{array}{l}\text { Convenção sobre Zonas Úmidas, } 1971 \text { (pro- } \\
\text { mulgada pelo Dec. 1905/96) }\end{array}$ & $-x-$ & $\begin{array}{l}\text { Áreas de Reconhecimento Interna- } \\
\text { cional }\end{array}$ & Sítios Ramsar \\
\hline & \begin{tabular}{|l|}
$\begin{array}{l}\text { Conv. Patrimônio Mundial, } 1972 \text { (promulga- } \\
\text { da pelo Dec. 80978/1977) }\end{array}$ \\
\end{tabular} & $-x-$ & $\begin{array}{l}\text { Áreas de Reconhecimento Interna- } \\
\text { cional }\end{array}$ & Sítios do Patrimônio Mundial Natural \\
\hline & $\begin{array}{l}\begin{array}{l}\text { Estatuto do Índio (Lei no } 6001 \text { de } \\
\text { 19/12/1973) }\end{array} \\
\end{array}$ & $-x-$ & Terras Indígenas & $\begin{array}{l}\text { Reserva Indígena, Parque Indígena, Colônia Agrícola } \\
\text { Indígena e Território Federal Indígena }\end{array}$ \\
\hline & $\begin{array}{l}\text { Lei de Criação das Estações Ecológicas } \\
\text { (Lei 6902/1981) }\end{array}$ & $-x-$ & Estação Ecológica & $-x-$ \\
\hline & $\begin{array}{l}\text { Lei de Criação das Áreas de Proteção } \\
\text { Ambiental (Lei 6902/1981) }\end{array}$ & $-x-$ & Área de Proteção Ambiental & $-x-$ \\
\hline & $\begin{array}{l}\text { Decreto de Criação das Reservas Ecológi- } \\
\text { cas (Dec. 89336/1984) }\end{array}$ & $-x-$ & Reserva Ecológica & $-x-$ \\
\hline & $\begin{array}{l}\text { Lei de Criação das ARIEs (Dec. 89336/ } \\
\text { 1984) }\end{array}$ & $-x-$ & $\begin{array}{l}\text { Área de Relevante Interesse Ecoló- } \\
\text { gico }\end{array}$ & $-x-$ \\
\hline & Lei de Criação das RPPNs (Lei 1922/1996) & $-x-$ & $\begin{array}{l}\text { Reserva Particular do Patrimônio Na- } \\
\text { tural }\end{array}$ & $-x-$ \\
\hline
\end{tabular}




\section{QUADRO 1: Evolução dos principais instrumentos de criação de Áreas Protegidas no Brasil (continuação)}

\begin{tabular}{|c|c|c|c|c|}
\hline PERÍODO & INSTRUMENTOS & $\begin{array}{l}\text { INSTRUMENTOS } \\
\text { INCORPORADOS }\end{array}$ & TIPOLOGIAS & CATEGORIAS \\
\hline \multirow[t]{2}{*}{$\begin{array}{l}\text { A partir } \\
\text { de } 2000\end{array}$} & \multirow[t]{2}{*}{ Novo Código Florestal (Lei 4771/1965) } & \multirow[t]{2}{*}{$\begin{array}{l}\text { Código Florestal (Dec. 23793/ } \\
\text { 1934) }\end{array}$} & Área de Preservação permanente & $\begin{array}{l}\text { 1) ao longo dos rios ou de qualquer curso d'água; } 2 \text { ) ao } \\
\text { redor das lagoas, lagos ou reservatórios d'água; } 3 \text { ) nas } \\
\text { nascentes e "ollos d'água" num raio de } 50 \mathrm{~m} \text { de largura; } \\
\text { 4) no topo de morros, montes, montanhas e serras; } 5 \text { ) } \\
\text { nas encostas ou partes destas, com declividade supe- } \\
\text { rior a } 45^{\circ} \text {, equivalente a } 100 \% \text { na linha de maior decli- } \\
\text { ve; } 6 \text { ) nas restingas, como fixadoras de dunas ou } \\
\text { estabilizadoras de mangues; 7) nas bordas dos tabu- } \\
\text { leiros ou chapadas, a partir da linha de ruptura do } \\
\text { relevo, em faixa nunca inferior a } 100 \mathrm{~m} \text { em projeçôes } \\
\text { horizontais; } 8 \text { ) em altlitude superior a } 1800 \mathrm{~m} \text {, qualquer } \\
\text { que seja a vegetaçăo. }\end{array}$ \\
\hline & & & Reserva Legal & $\begin{array}{l}\text { 1) } 80 \% \text { da PR } \text { PR }^{3} \text { Amazônia Legal; } 2 \text { ) } 35 \% \text { na PR em } \\
\text { área de cerrado localizada na Amazônia Legal; } 3 \text { ) } 20 \% \\
\text { na PR em área de floresta ou vegetação nativa nas } \\
\text { demais regiôes; 4) } 20 \% \text { na PR em área de campos } \\
\text { gerais em qualquer região. }\end{array}$ \\
\hline
\end{tabular}


QUADRO 1: Evolução dos principais instrumentos de criação de Áreas Protegidas no Brasil (continuação)

\begin{tabular}{|c|c|c|c|c|}
\hline PERÍODO & INSTRUMENTOS & $\begin{array}{l}\text { INSTRUMENTOS } \\
\text { INCORPORADOS }\end{array}$ & TIPOLOGIAS & CATEGORIAS \\
\hline \multirow{5}{*}{$\begin{array}{l}\text { A partir } \\
\text { de } 2000\end{array}$} & $\begin{array}{l}\text { Sistema Nacional de Unidades de Conser- } \\
\text { vação da Natureza (Lei 9985/2000) }\end{array}$ & $\begin{array}{l}\text { Lei de Proteção aos Animais (Lei } \\
\text { 5197/1967); Lei de Criação das } \\
\text { Estações Ecológicas e APAs (Lei } \\
\text { 6902/1981); Decreto de Criação } \\
\text { das RESECs e ARIEs (Dec. 89336/ } \\
\text { 1984); Lei de Criação das RPPNs } \\
\text { (Lei 1922/1996); parte do Novo } \\
\text { Código Florestal (Lei 4771/1965) }\end{array}$ & $\begin{array}{l}\text { Unidades de Proteção Integral (PI) e } \\
\text { Unidades de Uso Sustentável (US) }\end{array}$ & $\begin{array}{l}\text { PI: Estação Ecológica; Reserva Biológica; Parque Na- } \\
\text { cional; Monumento Natural; Refúgio de Vida Silvestre } \\
\text { US: Área de Proteção Ambiental; Área de Relevante } \\
\text { Interesse Ecológico; Floresta Nacional; Reserva } \\
\text { Extrativista; Reserva de Fauna; Reserva de Desenvol } \\
\text { vimento Sustentável; Reserva Particular do Patrimônio } \\
\text { Natural. }\end{array}$ \\
\hline & $\begin{array}{l}\text { Programa MaB, } 1970 \text { (Dec. } 74685 / 74 \text { e Dec. } \\
\text { Pres. 21/09/99) }\end{array}$ & $-x-$ & $\begin{array}{l}\begin{array}{l}\text { Áreas de Reconhecimento Internacio- } \\
\text { nal }\end{array} \\
\end{array}$ & Reserva da Biosfera \\
\hline & $\begin{array}{l}\text { Convenção sobre Zonas Úmidas, } 1971 \text { (pro- } \\
\text { mulgada pelo Dec. 1905/96) }\end{array}$ & $-x-$ & $\begin{array}{l}\text { Áreas de Reconhecimento Internacio- } \\
\text { nal }\end{array}$ & Sítios Ramsar \\
\hline & $\begin{array}{l}\text { Conv. Patrimônio Mundial, } 1972 \text { (promulga- } \\
\text { da pelo Dec. 80978/1977) }\end{array}$ & $-x-$ & $\begin{array}{l}\text { Áreas de Reconhecimento Internacio- } \\
\text { nal }\end{array}$ & Sítios do Patrimônio Mundial Natural \\
\hline & $\begin{array}{l}\text { Estatuto do Índio (Lei no 6001de 19/12/ } \\
\text { 1973) }\end{array}$ & $-x-$ & Terras Indígenas & $\begin{array}{l}\text { Reserva Indígena, Parque Indígena, Colônia Agrícola } \\
\text { Indígena e Território Federal Indígena }\end{array}$ \\
\hline
\end{tabular}

1 Para cada período mantiveram-se indicados todos os instrumentos criados em períodos anteriores mas que ainda encontram-se vigentes. Os novos instrumentos que substituíram ou incorporaram objetivos e/ou funções de seus antecessores também estão indicados no Quadro. 
Ao tratar a questão da proteção da natureza como responsabilidade da União e dos Estados, mesmo que de maneira resumida e pouco precisa, a Constituição de 1934 outorgava à natureza um novo valor, isto é, ela passava a ser considerada patrimônio nacional admirável a ser preservado. Com isso, sua proteção adquire novo sentido e status, consistindo em tarefa ou dever a ser cumprido e fiscalizado pelo poder público. Proteger a natureza entra na agenda governamental republicana, passando a configurar um objetivo em si da política desenvolvimentista nacional. É neste cenário que os principais dispositivos legais de proteção da natureza, que levaram à criação e consolidação das primeiras áreas protegidas, são criados contemporaneamente no Brasil: o Código Florestal (Decreto 23793/1934), o Código de Águas (Decreto 24643/1934), o Código de Caça e Pesca (Decreto 23672/1934) e o decreto de proteção aos animais (Decreto 24645/1934).

De todos eles, o Código Florestal foi o instrumento mais importante, pois definiu objetivamente as bases para a proteção territorial dos principais ecossistemas florestais e demais formas de vegetação naturais do país. Ele tinha como principais objetivos legitimar a ação dos serviços florestais, em franca implementação em alguns estados brasileiros desde o final do século XIX, além de regularizar a exploração do recurso madeireiro, estabelecendo as bases para sua proteção. Ele foi, também, o primeiro instrumento de proteção brasileiro a definir claramente tipologias de áreas a serem especialmente protegidas. Ele declarava de "interesse comum a todos os habitantes do país" o conjunto das florestas existentes e demais formas de vegetação, classificandoas em quatro tipologias: protetoras, remanescentes, modelo e de rendimento.

Eram do tipo protetoras as florestas que tivessem finalidade de conservar os regimes das águas, evitar a erosão, fixar dunas, assegurar a salubridade pública, proteger sítios, asilar espécimes da fauna, ou proteger, do ponto de vista militar, as fronteiras.

Florestas remanescentes eram aquelas declaradas pelo Poder Público Federal, Estadual ou Municipal, visando a criação de parques, inclusive pequenos bosques de gozo público e reservas de proteção biológica ou estética.

As florestas modelo e de rendimento eram aquelas que poderiam ser submetidas a manejo de recursos naturais, visando o extrativismo de madeira. Nelas figuravam as Florestas Nacionais.

Com o Código Florestal, foram criadas as condições necessárias para a formalização da criação do Parque Nacional de Itatiaia, antiga aspiração dos ambientalistas e pesquisadores da época. Fruto da "emancipação" de uma estação de pesquisas sob responsabilidade do Jardim Botânico do Rio de Janeiro, conhecida como "Estação Biológica de Itatiaia", o primogênito dos Parques Nacionais, já nas primeiras linhas do seu decreto de criação n $^{\circ} 1713$, datado de 14 de junho de 1937, indicava suas pretensões: manter a região onde se localiza "perpetuamente conservada no seu aspecto primitivo e atender às necessidades de ordem científica", além de "atender também às [finalidades] de ordem turística, que se apresentem em condições de fazer do Parque um centro de atração para viajantes, assim nacionais como estrangeiros".

Dois anos mais tarde, em 1939, mais dois novos Parques Nacionais somaram-se ao de Itatiaia: $\bigcirc$ Parque Nacional do Iguaçu, no Paraná, e o Parque 
Nacional da Serra dos Órgãos, no Rio de Janeiro. Entretanto, a criação de parques no Brasil arrefeceu nos 20 anos seguintes, quando nenhum outro foi criado. Somente a partir de 1959 é que ela novamente foi retomada de maneira mais expressiva, desta vez, atingindo as regiões norte, nordeste e centro-oeste do país (MEDEIROS, 2003).

Fenômeno semelhante sucedeu com as Florestas Nacionais federais que só foram instituídas pelo governo a partir da segunda metade dos anos 40. A Floresta Nacional de Araripe-Apodi, no Ceará, em 1946, foi a primogênita, seguida, quinze anos mais tarde, pela Floresta Nacional de Caxiuanã, no Pará (1961). Durante o período em que esteve vigente o Código de 34, nenhuma reserva de proteção biológica ou estética foi criada (MEDEIROS, 2003).

A implementação, administração e fiscalização dessas áreas foram subordinadas ao Serviço Florestal Federal, Seção de Parques e Florestas Nacionais, órgão vinculado ao Ministério da Agricultura. Tal fato reforçava um caráter protecionista signatário de uma tradição de proteção vinculada a uma escola essencialmente de administração florestal, onde a floresta era encarada como recurso econômico cuja exploração deveria ser controlada ou supervisionada pelo Estado (florestas modelo e de rendimento) ou resguardadas em função dos serviços ambientais por ela prestados (florestas protetoras e remanescentes).

O Código de Caça e Pesca de 1934, que anos mais tarde acabou desmembrado em um específico para a pesca e outro para a caça, também estabeleceu medidas que previam a instituição de áreas protegidas. Seu capítulo III indicava a destinação de "terras públicas do domínio da União, dos Estados e dos Municípios, a juízo dos respectivos Governos, [para o estabelecimento de] parques de criação e de refúgio". Alguns refúgios animais foram criados neste período, como no município de Linhares, no Espírito Santo, em 1943 (AGUIRRE, 1951).

Já o decreto que estabelecia medidas de proteção para a fauna e a flora não previa em seu texto a criação ou delimitação de áreas específicas para a proteção de animais em seus hábitats de origem, seguindo ainda a tradição de proteção centrada em espécies ou recursos e não em regimes especiais aplicados a espaços específicos.

A principal característica desse período foi trazer para a legislação brasileira os primeiros elementos capazes de garantir um regime diferenciado de proteção e gestão de parcelas do território brasileiro, embora efetivamente isso não tenha se refletido de forma expressiva no número de áreas instituídas.

É inegável, porém, que um importante aspecto do modelo de proteção que se construiu no país, nesse período, foi a sua capacidade de ter estabelecido, desde o início, distintas tipologias e categorias de áreas protegidas voltadas para uma gestão ambiental do território que garantisse, pelo menos conceitualmente, tanto a preservação e intocabilidade de áreas estratégicas quanto à conservação através da utilização controlada dos recursos naturais em áreas específicas. 


\section{B/ De 1965 a 2000}

A ascensão do regime militar, após a autoproclamada "revolução de 64", estabeleceu mudanças profundas no sistema político brasileiro. Entretanto, curiosamente, todos os instrumentos que possibilitaram a criação de áreas protegidas no Brasil foram mantidos em um primeiro momento e até mesmo aperfeiçoados posteriormente.

Tal prática, em princípio, não deve alimentar a equivocada noção de que os anos da ditadura foram deliberadamente corretos no aspecto ambiental. Ela teve suas raízes tanto no próprio processo de maturação e consolidação da sensibilidade política do país, ainda que tardia, para a problemática ambiental, como também foi conseqüência da mudança na percepção da comunidade internacional para os problemas ambientais. Neste caso específico, as mobilizações acabaram por gerar forte mobilização e uma agenda ambiental internacional positiva, da qual o Brasil tornouse signatário.

No ano seguinte ao estabelecimento do novo regime, em 1965, um novo Código Florestal foi apreciado no legislativo, sancionado pela Presidência da República e instituído através da Lei $n^{\circ} 4771$ de 15/09/1965. Basicamente, seus objetivos seguiam a mesma linha do seu antecessor. No entanto, ele extinguiu as quatro tipologias de áreas protegidas antes previstas na versão de 34 , substituindo-as por quatro outras novas: Parque Nacional e Floresta Nacional (anteriormente categorias específicas), as Áreas de Preservação Permanente (APP) e a Reserva Legal (RL). Estas duas últimas, uma tipificação de dispositivos existentes na versão de 34, eram uma clara tentativa de conter os avanços sobre a floresta. A primeira declarando intocável todos os espaços cuja presença da vegetação garante sua integridade (serviços ambientais) e, a segunda, transferindo compulsoriamente para os proprietários rurais a responsabilidade e o ônus da proteção (BRASIL, 1965).

Dois anos mais tarde, a nova Lei de Proteção aos Animais (Lei n5197/ 1967) trouxe significativo avanço em relação a sua antecessora. Ela passou a garantir em seu texto o direito à proteção de espécies animais em seus ambientes nativos e a criação de espaços específicos - os refúgios e reservas - destinados à sua preservação, além de outros específicos ao exercício da caça, já que a redação do Código de Caça em vigor nada previa neste sentido. Assim, em seu artigo $5^{\circ}$, definiu-se como função do poder público criar as Reservas Biológicas Nacionais, "onde as atividades de utilização, perseguição, caça, apanha, ou introdução de espécimes da fauna e flora silvestres e domésticas, bem como modificações do meio ambiente a qualquer título, são proibidas, ressalvadas as atividades científicas devidamente autorizadas pela autoridade competente", e os Parques de Caça Federais, "onde o exercício da caça é permitido aberto total ou parcialmente ao público, em caráter permanente ou temporário, com fins recreativos, educativos e turísticos" (BRASIL, 1967a).

Foi também somente em 1967 que houve a iniciativa de criação de um novo órgão no governo central com atribuições específicas para implementar, gerir e fiscalizar as áreas protegidas em franca expansão pelo território nacional. $\bigcirc$ Instituto 
Brasileiro de Desenvolvimento Florestal (IBDF), autarquia federal vinculada ao Ministério da Agricultura e instituída pelo Decreto-Lei Federal n²89 de 28/02/1967, nascia com a missão de "formular a política florestal bem como orientar, coordenar e executar ou fazer executar as medidas necessárias à utilização racional, à proteção e à conservação dos recursos naturais renováveis" (BRASIL, 1967b). Era de sua competência prioritária fazer cumprir o Código Florestal, a lei de proteção à fauna, toda a legislação pertinente aos recursos naturais renováveis, além de administrar o Jardim Botânico do Rio de Janeiro, os Parques Nacionais, as Florestas Nacionais, as Reservas Biológicas e os Parques de Caça Federais. Em outras palavras, criava-se uma instituição fortalecida e prestigiosa, com ambiciosa atribuição: gerir todos as áreas protegidas existentes no país.

Com a chegada dos anos 70, inaugura-se uma nova fase no ambientalismo mundial, cujos reflexos serão sentidos no cenário político brasileiro. A realização de diversos encontros internacionais, entre os quais destacam-se a Conferência da Biosfera (1968) e a Conferência de Estocolmo (1972), refletem o forte sentimento e a mobilização global para a implementação de uma agenda ambiental internacional (MEDEIROS, 2003).

Se por um lado, na Conferência de Estocolmo, em 1972, a delegação brasileira defendeu posições polêmicas, como a de que a poluição seria bem-vinda desde que trouxesse crescimento e desenvolvimento para o país, por outro, de forma ambivalente, o governo acabou adotando internamente um comportamento preventivo mais alinhado à tendência internacional de criar e/ou reforçar instituições específicas para tratar e conduzir a questão ambiental. E isto ocorreu em um momento político decisivo para o país, pois coincidiu com o início da discussão e implementação dos Planos Nacionais de Desenvolvimento (PND's) (RIBEIRO, 2001).

Logo ficou patente a necessidade de criação, no Brasil, de uma estrutura central capaz de elaborar, organizar, integrar e conduzir um verdadeiro projeto político nacional para o meio ambiente, com forte atuação no quadro interno, mas expressiva representatividade no cenário externo. Esta estrutura, instituída em 1973 sob a denominação de Secretaria Especial do Meio Ambiente (SEMA), nasceu sob o impacto dos debates decorrentes da Conferência de Estocolmo e do Clube de Roma. A SEMA, vinculada ao Ministério do Interior, foi criada a partir do Decreto n73030 em 30/10/ 1973, "orientada para a conservação do meio ambiente, e o uso racional dos recursos naturais", passando a dividir com o IBDF a responsabilidade pela gestão e fiscalização da política brasileira para as áreas protegidas.

Essas influências se confirmaram no texto do II PND (1975-79), que relacionava entre os seus objetivos "atingir o desenvolvimento sem deterioração da qualidade de vida e, em particular, sem devastar o patrimônio nacional de recursos naturais". Para a Amazônia, demandava uma "imediata designação de Parques Nacionais e Florestas Nacionais", como parte da política de desenvolvimento (BRASIL, 1975).

Contudo, com a criação da SEMA, esperava-se que esta fosse acumular todas as funções de gestão das áreas protegidas, deixando ao IBDF somente a 
responsabilidade de fomentar o desenvolvimento da economia florestal. Por razões de cunho político isto não ocorreu, uma vez que todo o conjunto de áreas criadas até então havia sido mantido sob gestão do IBDF. Com isso, a SEMA acabou estabelecendo um programa próprio de áreas protegidas que ficariam a ela subordinadas (MERCADANTE, 2001).

Este processo teve como resultado, após alguns anos de estudo, a proposição inicial de quatro novas tipologias de áreas protegidas pela SEMA: as Estações Ecológicas (ESEC) e as Áreas de Proteção Ambiental (APA), em 1981, além das Reservas Ecológicas (RESEC) e das Áreas de Relevante Interesse Ecológico (ARIE), em 1984. Mais tarde, em 1996 e já com a SEMA alçada ao status de Ministério, foram criadas as Reservas Particulares do Patrimônio Natural (RPPNs), uma nova tipologia que permitia o reconhecimento de uma área protegida em domínio privado. A criação das RPPNs representou um importante avanço, pois permitiu e estimulou a criação voluntária de áreas protegidas pela sociedade.

A justificativa principal para a instituição dessas novas tipologias era o preenchimento de lacunas evidentes no modelo brasileiro de criação de áreas protegidas. Assim, as instituição das APAs, tipologia inspirada no modelo de Parques Naturais Regionais europeus, visava estabelecer um modelo de proteção que resguardasse áreas com certo nível de ocupação, sobretudo em áreas urbanas, sem a necessidade da União adquirir essas terras. As RESECs, por sua vez, objetivavam criar "santuários ecológicos" e preservar espécies endêmicas ameaçadas de extinção.

Contudo, a existência de duas agências governamentais com tarefas similares duplicava o esforço do governo e era evidente que as novas tipologias criadas pela SEMA apresentavam certo grau de sobreposição em relação àquelas subordinadas ao IBDF. Em termos práticos, para citar apenas um exemplo, as ESECs da SEMA e as REBIOs do IBDF cumpriam objetivos muito próximos.

Além disso, estudos desenvolvidos no âmbito do IBDF já apontavam, desde meados da década de 70, para a necessidade de promover uma maior ordenação no processo de criação de áreas protegidas, especialmente para a região amazônica, através de sua reorganização sob a forma de um sistema único e integrado (WETTERBERG, 2004). Estes estudos e debates foram a base para a construção de uma proposta que contemplava a criação de um sistema de "Unidades de Conservação" no Brasil. Duas propostas, uma de 1979 e outra de 1982, foram os embriões para o que mais tarde seria, como veremos mais adiante, o SNUC.

Antes, porém, é necessário registrar ainda que este período foi extremamente importante por duas outras razões: o reconhecimento das Terras Indígenas e de diversas áreas especialmente protegidas em função de acordos internacionais dos quais o Brasil se tornou signatário ou estava comprometido.

As Terras Indígenas constituem um avanço significativo da política brasileira no sentido de reconhecer os direitos dos primeiros povos que habitavam o Brasil antes da chegada do colonizador. A idéia do governo de demarcar terras para os índios surgiu no início do século XX, com o Serviço de Proteção aos Índios (SPI) em 1910. No entanto, como afirma BAINES (2001), a política de demarcação de terras 
indígenas somente ganhou maior efetividade com a criação da FUNAI, em 1967, em substituição ao SPI, e com a instituição do Estatuto do Índio, em 1973. Este último forneceu as bases legal e administrativa para que as demarcações de Terras Indígenas fossem realizadas em quatro diferentes categorias: Reserva Indígena, Parque Indígena, Colônia Agrícola Indígena e Território Federal Indígena.

Durante anos as Terras Indígenas não foram consideradas como área protegida no sentido estrito do termo. Contudo, elas sempre representaram um importante instrumento de conservação e manejo da biodiversidade pelas populações autóctones. $\bigcirc$ artigo 28 do Estatuto do Índio já reforçava esta idéia, ao determinar que, no caso específico dos Parques Indígenas, fosse garantida a preservação "das reservas de flora e fauna e as belezas naturais da região".

Além disso, o próprio Código Florestal ratificou a importância das terras indígenas no processo de conservação ao declarar, em seu artigo $3^{\circ}$, que "as florestas que integram o Patrimônio Indígena ficam sujeitas ao regime de preservação permanente".

Embora garantido nos instrumentos legais, o caráter conservacionista das Terras Indígenas brasileiras e sua integração à política nacional de gestão das áreas protegidas foi reforçado somente a partir dos anos 90 com o Programa Piloto de Proteção das Florestas Tropicais do Brasil (PPG7). O PPG7, um dos maiores programas ambientais desenvolvidos no Brasil, contribuiu para a integração da política indígena brasileira à política ambiental através do Projeto Integrado de Proteção às Populações e Terras Indígenas da Amazônia Legal (PPTAL). Seu objetivo é "apoiar projetos de educação ambiental, manejo de unidades de conservação, fortalecimento de instituições de pesquisa e proteção às terras indígenas" (FUNAI, 2000), garantindo às terras indígenas localizadas na Amazônia Legal financiamento para sua demarcação. Para BECKER (2004), estas ações possibilitaram significativo avanço no reconhecimento e na demarcação de várias Terras Indígenas.

Foi também a partir dos anos 70 que diversas iniciativas, no sentido de criação ou reconhecimento internacional de áreas de relevante interesse ecológico ou cultural, começaram a ser discutidas e implementadas. A lógica deste processo era a de estimular e fomentar a conservação de áreas representativas e singulares ao redor do mundo e, ao mesmo tempo e em alguns casos, estabelecer áreas demonstrativas onde pesquisas científicas pudessem ser realizadas.

No Brasil, três foram estes instrumentos que se traduziram na efetiva criação ou no reconhecimento de áreas protegidas: o Programa "O Homem e a Biosfera - MaB”, a Convenção sobre Zonas Úmidas e a Convenção do Patrimônio Mundial.

$\bigcirc$ Programa "O Homem e a Biosfera - MaB" foi lançado oficialmente pela UNESCO em 1970 e um de seus projetos consistia efetivamente em estabelecer uma "rede mundial coordenada" de novas zonas protegidas que seriam designadas com "Reservas da Biosfera", em referência ao próprio nome do Programa (UNESCO, 2001). No total, seis são as Reservas da Biosfera criadas no país: RB da Mata Atlântica (1993), RB do Cerrado (1993), RB do Pantanal (2000), RB da Caatinga (2001), RB da Amazônia Central (2001) e RB da Serra do Espinhaço (2005) (MEDEIROS, 2005). 
A Convenção sobre Zonas Úmidas, estabelecida em 1971, previa o reconhecimento de Sítios de Importância Internacional, denominados "Sítios Ramsar" em referência à cidade iraniana onde a conferência se realizou. O Brasil, quarto país do mundo em superfície na Lista Ramsar, ratificou a convenção em setembro de 1993 e desde então oito zonas foram reconhecidas como Sítios Ramsar (MEDEIROS, 2005).

A Convenção do Patrimônio Mundial foi oficializada pela UNESCO em 1972. Seu objetivo era garantir a proteção das obras e áreas de grande interesse para a história da Terra ou da cultura da humanidade. Dentre as categorias previstas pela convenção estão os bens naturais, selecionados por sua beleza excepcional ou sua importância geológica ou biológica. Estas áreas são chamadas de Sítios do Patrimônio Natural Mundial. Os primeiros sítios brasileiros a serem inscritos na lista do Patrimônio Mundial, na década de oitenta, foram sítios culturais, graças à ação do IPHAN. Atualmente são sete os sítios naturais inscritos na lista da UNESCO (MEDEIROS, 2005).

\section{C/ A partir de 2000}

O ano de 2000 marcou uma importante modificação na estrutura de grande parte das áreas protegidas brasileiras. Nele, finalmente foi concretizada a ambição surgida no final dos anos 70 de estabelecer um sistema único - o Sistema Nacional de Unidades de Conservação da Natureza (SNUC) - que definiria critérios mais objetivos para a criação e gestão de algumas tipologias e categorias de áreas protegidas que antes se encontravam dispersas em diferentes instrumentos legais.

Sua criação, como já mencionamos, remonta ao ano de 1979, quando o IBDF, em conjunto com a FBCN, apresentou um estudo intitulado "Plano do Sistema de Unidades de Conservação do Brasil” (IBDF/FBCN, 1979). Este documento, cuja segunda versão revisada foi lançada em 1982, tinha por objetivo identificar as áreas mais importantes para a conservação da natureza no país, propondo a criação de um conjunto integrado de áreas protegidas (IBDF/FBCN, 1979; IBDF/FBCN, 1982). Uma das novidades deste documento era a utilização da terminologia Unidades de Conservação para designar o conjunto de áreas protegidas que seriam contempladas pelo sistema. Esta proposta, no entanto, por razões políticas, acabou não se mostrando viável (MERCADANTE, 2001; MEDEIROS, 2003).

Posteriormente, em 1988, o IBDF novamente encomendou, desta vez à Fundação Pró-Natureza (Funatura), um estudo sobre as categorias de proteção então existentes no país e a elaboração de um anteprojeto de lei voltado para a criação de um Sistema Nacional de Unidades de Conservação. Um ano mais tarde, após debates envolvendo técnicos do governo e representantes de entidades civis, a Funatura entregou ao já constituído IBAMA a proposta de anteprojeto (MERCADANTE, 2001). Nela, previa-se a criação das chamadas Unidades de Conservação (UCs) em nove categorias distintas, organizadas em três grupos (BRASIL, 1989): 
- UCs de Proteção Integral: Parque Nacional, Reserva Ecológica (fusão da Reserva Biológica com a Estação Ecológica), Monumento Natural e Refúgio da Vida Silvestre (absorvendo os objetivos da Área de Relevante Interesse Ecológico, que seria extinta).

- UCs de Manejo Provisório: Reserva de Recursos Naturais.

- UCs de Manejo Sustentável: Reserva de Fauna (em substituição aos

Parques de Caça), Área de Proteção Ambiental e Reserva Extrativista.

Em maio de 1992, este anteprojeto foi apresentado ao então presidente Fernando Collor de Mello pela Secretaria do Meio Ambiente, que o encaminhou ao Congresso Nacional sob a forma agora do Projeto de Lei n²892/92.

A história da longa tramitação até a aprovação deste projeto nas duas casas legislativas e sua sanção final pelo Presidente da República é recheada de fatos que só serviram para revelar e demarcar mais claramente as diferentes posições existentes entre os movimentos ambientalistas no Brasil, acentuando ainda mais as suas divergências. Ao longo de extensos oito anos de debates que incluíram a apresentação de dois substitutivos na Câmara, preservacionistas, conservacionistas, socioambientalistas e ruralistas travaram uma verdadeira batalha que mobilizou a imprensa, ONGs, além de fortíssimos lobbys no Congresso na defesa de suas posições sobre a forma e os critérios de proteção da natureza. Entre os pontos mais polêmicos destacavam-se a questão das populações tradicionais, a participação popular no processo de criação e gestão de UCs e as indenizações para desapropriações. Para MERCADANTE (2001), em maior extensão, uma visão mais preservacionista, muito próxima do projeto original elaborado pela Funatura, acabou prevalecendo no texto final que foi aprovado pelo Congresso, no ano de 2000, com significativo apoio da Casa Civil da Presidência da República. Em seu texto final, dado pela Lei 9985/ 2000, ficou definida a criação de 12 categorias de Unidades de Conservação, reunidas em dois grupos: Unidades de Proteção Integral e Unidades de Uso Sustentável (vide QUADRO 1).

A organização em dois grupos buscava contemplar estratégias distintas de gestão dessas áreas que, em certo grau, estava no centro das disputas entre os diferentes grupos interessados na questão. Assim, as Unidades de Proteção Integral, segundo o texto do SNUC, têm por objetivo "preservar a natureza, sendo admitido apenas o uso indireto dos seus recursos naturais" (art. $7^{\circ}, \S 1^{\circ}$ ). Já as Unidades de Uso Sustentável visam "compatibilizar a conservação da natureza com o uso sustentável de parcela dos seus recursos naturais" (art. $7^{\circ}, \S 2^{\circ}$ ). Por uso sustentável, esta lei indicou como entendimento a "exploração do ambiente de maneira a garantir a perenidade dos recursos ambientais renováveis e dos processos ecológicos, mantendo a biodiversidade e os demais atributos ecológicos, de forma socialmente justa e economicamente viável" (art. $2^{\circ}$, inciso XI).

O SNUC foi um instrumento que não apenas incorporou de uma única vez parte das áreas protegidas prevista pela legislação brasileira até então, como abriu espaço para que novas categorias fossem criadas ou incorporadas a partir de experiências originais desenvolvidas no país. 
Esse foi o caso das Reservas Extrativistas (RESEX), categoria, como indica BECKER (2004:107), "fruto da luta dos seringueiros por sua sobrevivência na floresta, contra a expansão dos fazendeiros de gado e os projetos de colonização do INCRA". Este é um típico projeto estruturado a partir da base, cuja organização e pressão fez com que as primeiras Reservas Extrativistas criadas em 1989, no estado do Acre, fossem legitimadas e reconhecidas oficialmente pelo governo federal através do SNUC.

Um outro exemplo são as Reservas de Desenvolvimento Sustentável (RDS), que ao contrário das RESEX, não partiram da base mas foram originadas diretamente de interesses científicos e preservacionistas. A origem desta categoria está intrinsecamente ligada ao Projeto Mamirauá, localizado na Várzea do Médio Vale do Solimões, no Estado do Amazonas, que durante um curto período de tempo funcionou como uma Reserva Ecológica estadual. Mas a evidente inadequação desta categoria às expectativas demandadas para a área, tanto pelos cientistas, como pela própria comunidade local, levou à proposição de uma nova categoria, a RDS, que foi prontamente implementada pelo governo estadual. Os desafios a serem enfrentados, neste caso, foram a necessidade de compatibilizar a preservação de espécies endêmicas ameaçadas de extinção com os modos de vida de populações ribeirinhas.

As RESEX e as RDS representam um importante avanço na concepção de áreas protegidas no Brasil, pois incorporam concretamente aos objetivos da conservação ações de inclusão social e econômica das populações diretamente afetadas. É um modelo que contribui efetivamente para a redução de um dos principais obstáculos ao pleno funcionamento das áreas protegidas: os conflitos fundiários.

No entanto, estas iniciativas, se originais e inovadoras, ainda parecem não estar devidamente consolidadas na práxis política de criação de novas áreas, tendo em vista que, até 2004, nenhuma outra RDS havia sido instituída pelo governo federal, estando elas circunscritas apenas às iniciativas de governos estaduais, sobretudo na região amazônica.

Ainda relativo ao SNUC, um outro aspecto importante foi a inclusão, em seu texto, de um capítulo específico dedicado às Reservas da Biosfera, que ganharam o status de categoria especial. Este fato, que está diretamente relacionado à forte atuação de setores ligados a criação e gestão destas áreas no país, naquele momento já bem organizados, é bastante curioso, uma vez que o mesmo tratamento não foi dado às outras Áreas com Reconhecimento Internacional também existentes no país.

Contudo, é inegável o avanço que se processou no Brasil em relação à temática proteção da natureza com a instituição do SNUC. De um dos países que mais tardiamente desenvolveu instrumentos legais que criassem as condições necessárias ao estabelecimento de áreas protegidas territorialmente demarcadas, em período relativamente curto ampliaram-se às possibilidades criando-se, de maneira extremamente original em alguns casos, novas formas de proteção. Tal fato é constatado pelo expressivo número e a extensão destas áreas implementadas no país até o momento (TABELA 1). 


\section{TABELA 1: Total de áreas protegidas no país por tipologia}

\begin{tabular}{l|c|c|c|c}
\hline \multicolumn{1}{c|}{ Tipologia } & N & Extensão & $\begin{array}{c}\text { Área Continental }^{1} \\
\text { do Brasil }\end{array}$ & $\%$ \\
\hline Unidade de Conservação $^{2}$ & 682 & $61.875 .888,68^{3}$ & & 7,2 \\
Área de Preservação Permanente & - & - & & - \\
Reserva Legal & - & - & $854.546 .635,67$ & - \\
Terra Indígena & 580 & $98.954 .645,00^{4}$ & & 11,6 \\
Áreas de Reconhecimento Internacional & 20 & $135.248 .422,77$ & & 15,8 \\
Total & 1282 & $296.078 .956,45$ & $854.546 .635,67$ & $34,6^{5}$ \\
\hline
\end{tabular}

${ }^{1}$ Expressa em hectares. ${ }^{2}$ Apenas UCs federais. ${ }^{3}$ Não inclui as RPPNs. ${ }^{4}$ Não inclui 139 TIs em fase de identificação. ${ }^{5}$ Em função da sobreposição de tipologias e categorias, não pode ser considerado como extensão total de cobertura. Fontes: Dados obtidos a partir do cruzamento de informações disponíveis no MMA/DAP (www.mma.gov.br/ index.cfm?id_estrutura $=48$ ) e no IBAMA (www.ibama.gov.br) para UCs e ARIs, e FUNAI (www.funai.gov.br) para TIs.

\section{CONSIDERAÇÕES SOBRE A ARTICULAÇÃO DO ATUAL MODELO BRASILEIRO PARA ÁREAS PROTEGIDAS E SEUS REFLEXOS SOBRE SUA GESTÃO FUTURA}

O SNUC, apesar do inegável avanço que proporcionou à questão das áreas protegidas no Brasil, não conseguiu atingir plenamente sua pretensão inicial de criação de um sistema que pudesse integrar, por meio de um único instrumento, a criação e gestão das distintas tipologias existentes no país. Se, por um lado, ele tem o mérito de racionalizar e otimizar em parte esta questão, ele também aprofundou a divisão existente entre as diferentes tipologias de áreas protegidas que ficaram excluídas do seu texto.

Ao consolidar, mesmo que não intencionalmente, as Unidades de Conservação como tipologia dotada de maior visibilidade e expressão, e dotá-las de instrumentos mais concretos de gestão, as outras tipologias que ainda continuaram a existir mesmo após a criação do SNUC - as APPs, as RLs, as TIs e as ARIs - continuaram relegadas aos mesmos problemas históricos de gestão e, mais grave, não dispondo de instrumentos de integração e articulação com as ações previstas para as Unidades de Conservação.

Um segundo aspecto, nesse caso extremamente positivo, no processo de gestação e instituição do SNUC, foi sua capacidade de reconhecer que as ações só teriam maior efetividade se estas fossem organizadas de forma integrada e sistemática. O tempo relativamente longo empreendido até sua efetiva concretização, contudo, não desmerece a originalidade e o avanço da proposta. Pelo contrário, só evidencia as dificuldades existentes neste campo em virtude das disputas cada vez mais acirradas entre os diferentes grupos que atuam ou têm interesse nesta área no Brasil. Tal fato pode também ser inegavelmente constatado no debate que se arrasta há anos no Congresso Nacional com relação à revisão do Código Florestal. 
No entanto, apenas a existência dos instrumentos, do sistema e das instituições responsáveis não garante sua efetividade ou eficiência. Para tal, mecanismos mais sólidos e perenes de planejamento e financiamento se fazem necessários. A falta de planejamento de longo prazo e o aporte de recursos têm sido os principais gargalos na consolidação das áreas protegidas brasileiras. Boa parte deste problema advém da fraca tradição brasileira de estabelecer políticas e/ou planos de ação que sejam capazes de trabalhar com cenários desejados, porém realistas, no planejamento desta questão.

Esforços no sentido de construir uma agenda que traga para o centro dos debates e das ações as áreas protegidas e não mais apenas as Unidades de Conservação, uma distorção recente do modelo brasileiro, como já discutido, incluem a construção de uma Política e de um Plano Nacional de Áreas Protegidas, num processo liderado pela Diretoria de Áreas Protegidas do MMA a partir de 2003 (FERREIRA, 2004; BARROS, 2004). Boas partes dessas ações têm sido estimuladas:

- de maneira negativa: a) pela falência da gestão de áreas territorialmente extensas, como as APPs, que não dispõem de uma estratégia concreta e para onde o desmatamento tem conquistado maior terreno nos últimos anos; b) pelos conflitos e tensões ainda existentes nas áreas de contato entre Unidades de Conservação, terras indígenas e terras devolutas passíveis de grilagem e especulação;

- de maneira positiva: a) pela agenda discutida e estabelecida pele Acordo de Durban, durante o V Congresso Mundial de Parques em 2003; b) pelo Plano de Trabalho sobre Áreas Protegidas da CDB, aprovado durante a COP7 na Malásia, em 2004.

Da mesma forma, é preciso ainda estabelecer com maior precisão a integração das áreas protegidas com as diversas escalas de planejamento e gestão do território, hoje formalmente identificadas através dos mosaicos e dos corredores ecológicos. $\mathrm{O}$ próprio SNUC reconhece e consagra em seu texto a importância dessas ferramentas para o processo de gestão das áreas protegidas, porém, na prática, as experiências e os resultados são ainda muito pouco numerosos e bem avaliados.

Todas essas lacunas e questões discutidas neste estudo são em grande parte decorrentes do próprio processo de construção das áreas protegidas no país que, em diferentes momentos políticos, como pretendemos demonstrar, procurou atender às demandas mais imediatas do conservacionismo nacional. A culminância deste processo - a instituição do SNUC - entretanto, não conseguiu contemplar em definitivo uma solução para todos os problemas de baixa integração e gerenciamento dessas áreas, seja por falta de consenso político, seja mesmo por falta de percepção mais ampla para estes problemas à época. Quiçá essa mesma tenha sido sua pretensão.

Desta forma, passados cinco anos desde a sua implementação, talvez seja oportuna e apropriada a revisão e discussão dos objetivos e resultados obtidos até o momento sob a gestão do SNUC, de forma a colher subsídios valiosos para o aperfeiçoamento da estratégia nacional para as áreas protegidas. $\mathrm{O}$ "SNUC +5" seria 
uma oportunidade interessante para toda a sociedade, representada pelos atores e pelas instituições envolvidas com o tema, para discutir o modelo atual a partir das experiências concretas desenvolvidas nos últimos cinco anos, indicando caminhos e soluções de curto, médio e longo prazos que poderiam ser incorporadas ao processo de gestão de áreas protegidas no Brasil. Parece oportuno, da mesma forma, a necessidade de discussão de um novo sistema mais amplo e orientado ao ordenamento das áreas protegidas no Brasil - o Sistema Nacional de Áreas Protegidas (SNAP) - cuja instituição poderia em definitivo contribuir para a integração das distintas tipologias, ações e estratégias hoje em curso no país.

\section{REFERÊNCIAS BIBLIOGRÁFICAS}

AGUIRRE, A.. Soóretama - Estudo sobre o parque da reserva, refúgio e criação de animais silvestres, "Soóretama", no município de Linhares, Estado do Espírito Santo. Rio de Janeiro: Min. Agricultura-Serviço de Informação Agrícola. 1951, 49p.

BAINES, S.G. As terras indígenas no Brasil e a "regularização" da implantação de grandes usinas hidrelétricas e projetos de mineração na Amazônia. Brasília: UnB.2001 Mimeo.

BARRETTO FILHO, H. T. Notas para uma história social das áreas de proteção integral no Brasil. In: RICARDO, F. (org.) Terras Indígenas e Unidades de Conservação. São Paulo: Instituto Sócioambiental. 2004, pp.53-63.

BARROS, A. C. A Construção da política nacional de áreas protegidas fortalecendo as estratégias de conservação, uso e repartição de benefícios da biodiversidade no Brasil. Anais do IV Congresso Brasileiro de Unidades de Conservação, vol 2. Curitiba: Fundação $\bigcirc$ Boticário de Proteção à Natureza \& Rede Pró Unidades de Conservação. 2004, p.177-186.

BECKER, B. K. Brasil - Tordesilhas, ano 2000. Revista Território, Rio de Janeiro, ano IV, n 7, 1999, p. 7-23.

BECKER, B. K. Amazônia: Inserção internacional e soberania nacional. Brasília: SUDAM/ PRODEAM-PDA. 2000, 82p. mimeo

BECKER, B. K. Síntese do processo de ocupação da Amazônia. In: MMA (ORG.) Causas e dinâmica do desmatamento na Amazônia. Brasília: MMA. 2001, pp. 5-28.

BECKER, B. K. Amazônia: geopolítica na virada do III milênio. Rio de Janeiro: Ed. Garamond. 2004, 172p.

BRASIL, 1965. Lei 4771 de 15/09/1965 que institui o novo código florestal. Disponível em http://www.planalto.gov.br/ccivil_03/Leis/L4771.htm. Acessado em 13/06/2005.

BRASIL, 1967a. Lei n 5197 de 03/01/1967 que dispõe sobre a proteção à fauna e dá outras providências. Disponível em https:/www.planalto.gov.br/ccivil_03/leis/15197.htm. Acessado em 20/12/2005.

BRASIL, 1967b. Decreto-Lei n²89 de 28/02/1967 que cria o Instituto Brasileiro de Desenvolvimento Florestal e dá outras providências. Disponível em https:// www.planalto.gov.br/ccivil_03/del/del289.htm. Acessado em 20/12/2005. 
BRASIL. 1975. II PND - Plano Nacional de Desenvolvimento (1975-79). Brasília:SEPLAN BRASIL, 1989. Anteprojeto de Lei do Sistema Nacional de Unidades de Conservação. Brasília:IBAMA. 8p.

BRASIL. 2000. Lei 9985/00 que Institui o Sistema Nacional de Unidade de Conservação da Natureza.

CARVALHO, J. A conservação da natureza e dos recursos naturais na amazônia brasileira. In: Simpósio sobre a biota amazônica 7, 1967:1-47.

CABRAL, N. R. A. J. \& SOUZA, M. P. Área de Proteção Ambiental: planejamento e gestão de paisagens protegidas. São Carlos: Rima Editora. 2002, 154p.

CASTRO, C. A gestão florestal no Brasil colonial. Brasília: Ed. UNB, 2002.

COSTA, J. P. O. Áreas Protegidas. Artigo disponível em http://www.mre.gov.br/cdbrasil/ itamaraty/web/port/meioamb/arprot/apresent/apresent.htm. Acessado em 12/06/ 2003.

CUNHA, L. H. \& COELHO, M. C. N. Política e Questão Ambiental. In: CUNHA, S. B. \& GUERRA, A. J. T. (org.). A Questão Ambiental - Diferentes Abordagens Rio de Janeiro: Ed. Bertrand Brasil, 2003. 248p.

DEAN, W. A Ferro e Fogo: A História da Devastação da Mata Atlântica Brasileira. São Paulo: Cia das Letras, 2002 484p.

DIEGUES, A. C. O mito moderno da natureza intocada. São Paulo: Ed. Hucitec.2001 $161 \mathrm{p}$.

DRUMMOND, J.A. Devastação e preservação ambiental: os Parques Nacionais do Estado do Rio de Janeiro. Niterói:EdUFF, 1997.

FERREIRA, I. V. Uma política nacional para as áreas protegidas brasileiras. Anais do IV Congresso Brasileiro de Unidades de Conservação, vol 2. Curitiba: Fundação $\bigcirc$ Boticário de Proteção à Natureza \& Rede Pró Unidades de Conservação. 2004, p. 172-176.

FUNAI. Participando do PPTAL: Projeto Integrado de Proteção às Populações e Terras Indígenas na Amazônia Legal. Brasília: Funai, 2000.

IBDF/FBCN. Plano do sistema de unidades de conservação do Brasil. Brasília:Min. da Agricultura. 1979, $107 \mathrm{p}$.

IBDF/FBCN. Plano do sistema de unidades de conservação do Brasil: II Etapa. Brasília:Min. da Agricultura. 1982, 173p.

LANGLEY, S. The system of protected areas in the United States. In: BENJAMIN, A.H. (org.) Direito Ambiental das Áreas Protegidas: o regime jurídico das unidades de conservação. Rio de Janeiro: Ed. Forense, 2001. p. 116-161.

LARRÈRE, C. \& LARRÈRE, R. 1999. Comment sortir de la modernité? In: YOUNES, C. (ed.) Ville Contre-nature. Philosophie et Architecture. Paris: La Découverte, p. 4766.

MEDEIROS, R. A Proteção da Natureza: das Estratégias Internacionais e Nacionais às demandas Locais. Rio de Janeiro: UFRJ/PPG. 2003, 391p. Tese (Doutorado em Geografia).

MEDEIROS, R. A política de criação de áreas protegidas no Brasil: evolução, contradições e conflitos. Anais do IV Congresso Brasileiro de Unidades de 
Conservação, vol 1. Curitiba: Fundação $\bigcirc$ Boticário de Proteção à Natureza \& Rede Pró Unidades de Conservação, 2004.

MEDEIROS, R.; IRVING, M.; GARAY, I. A Proteção da Natureza no Brasil: evolução e conflitos de um modelo em construção. RDE. Revista de Desenvolvimento Econômico, n V, ano VI, no. 9, 2004, p. 83-93.

MEDEIROS, R. Singularidades do sistema de áreas protegidas para a conservação e uso da biodiversidade brasileira. In: GARAY, I. \& BECKER, B. (orgs.) Dimensões Humanas da Biodiversidade. Petrópolis: Editora Vozes, 2005 (no prelo).

MERCADANTE, M. A batalha do código florestal: algumas lições. Palestra proferida no 4을 Congresso Internacional de Direito Ambiental, Instituto o Direito por um Planeta Verde, São Paulo, 2000. mimeo.

MERCADANTE, M. Uma década de debate e negociação: a história da elaboração da Lei do SNUC. In: BENJAMIN, A.H. (org.) Direito Ambiental das Áreas Protegidas. Rio de Janeiro: Ed. Forense Universitária, 2001, p. 190-231.

MILANO, M.S. 2001. Unidades de Conservação - Técnica, Lei e Ética para a Conservação da Biodiversidade. In: In: BENJAMIN, A.H. (org.) Direito Ambiental das Áreas Protegidas. Rio de Janeiro: Ed. Forense Universitária, 2001, p. 03-41.

MIRANDA, E. E. Água na natureza, na vida e no coração dos homens. São Paulo: Campinas, 2004. Disponível em: <http://www.aguas.cnpm.embrapa.br>. Acesso em: 13 julho 2005.

ONF, Colbert et les Bois de Marine. Office National de Forêts, 2003. Disponível em http://www.onf.fr/foret/dossier/berce/1_1.htm. Acessado em 19/03/2003.

PADUA, J.A. Um sopro de destruição - Pensamento político e crítica ambiental no Brasil escravista (1786-1888). Rio de Janeiro: Jorge Zahar Editor, 2003, 318p.

RIBEIRO, W. C. A Ordem Ambiental Internacional. São Paulo: Editora Contexto, 2001, $176 \mathrm{p}$.

UICN. Guidelines protected Area Management Categories. Gland: UICN, 1994.

UNESCO. Biosphere reserves : special places for people and nature. Paris:UNESCO, 2001.

WETTERBERG, G. B. 2004. The concept of protected area system based on pleistocene refuges. In: MILANO, M. et al (Orgs). Unidades de Conservação: Atualidades e tendências. Curitiba: Editora Fundação $\bigcirc$ Boticário de Proteção à Natureza, 2004, p.76-91.

WIEDMANN, S.M.P. As Reservas Particulares do Patrimônio Natural. In: Anais do I Congresso Brasileiro de Unidades de Conservação. Curitiba:Universidade Livre do Meio Ambiente, 1997, p.3-14. 


\section{NOTAS}

1. O Estados Unidos pode ser considerado o berço onde nasceram os Parques Nacionais. O Parque Nacional de Yellowstone, em 1872, foi o primeiro de uma série a ser implementado em território norte-americano por meio de uma política que ficou conhecida como proteção da "wilderness", ou seja, de uma natureza selvagem e intocada (DIEGUES, 2001, LANGLEY, 2001; MILANO, 2001)

2. Decreto Estadual no 335, de 10 de fevereiro de 1896. Atualmente denominado de Parque Estadual Alberto Löefgren, sede do Instituto Florestal de São Paulo.

3. Até 1910, não somente os Estados Unidos, mas também Canadá (1885), Nova Zelândia (1894), Austrália (1898), África do Sul (1898), México (1898) e Argentina (1903) já haviam criados Parques Nacionais (MEDEIROS, 2003).

4. É fundamental sublinhar neste momento que os termos "tipologia" e "categoria" tal como definidos e utilizados ao longo deste trabalho indicam tão somente uma organização hierarquizada da criação de áreas protegidas no Brasil. Neste caso, uma "tipologia" expressa um tipo único e exclusivo de área protegida legalmente previstas ou reconhecidas pelo poder público (por exemplo, unidade de conservação ou reserva legal), enquanto uma "categoria" indica as subdivisões ou níveis inferiores de classificação de uma dada tipologia (por exemplo, a tipologia "unidade de conservação" é composta por várias categorias como APA, Reserva Biológica etc). Como veremos, este critério não é rígido, pois foi comum no sistema brasileiro que uma determinada tipologia se tornasse categoria e vice-e-versa à medida que os instrumentos se modificavam e se substituíam.

5. O grifo indica as diferentes categorias que estavam previstas para cada tipologia estabelecida pelo Código Florestal.

6. Decreto-Lei n 794 de 19/10/1938.

7. Decreto-Lei $n^{\circ} 1210$ de 12/04/1939, substituído definitivamente pelo decreto-lei n5894 de 20/10/1943.

8. Uma expressão concreta desse fato é atestada pelo significativo número de tratados e convenções internacionais das quais o Brasil se torna signatário - mais de 20 até a década de 70 (MEDEIROS, 2003).

9. Lei n6902 de 27/04/1981

10. Decreto n`89336, de 31/01/1984

11. a criação das RPPNs de fato representou a consolidação de iniciativas anteriores que com pouco sucesso tentaram estabelecer áreas protegidas privadas - os chamados "Refúgios Particulares de Animais Nativos", instituído em 1977 pelo IBDF, e, posteriormente, as "Reservas Particulares de Fauna e Flora" criadas pelo IBAMA em 1988, em substituição a anterior. Mais detalhes podem ser obtidos em WIEDMANN, 1997.

12. Lei $n^{\circ} 5371$ de $05 / 12 / 1967$

13. Lei $n^{\circ} 6001$ de $19 / 12 / 1973$

14. incluindo a Reserva da Biosfera do Cinturão Verde de SP

15. e isto pode ser evidenciado por meio de uma série de mecanismos e instrumentos positivos previstos em seu texto, entre eles, o que garante a participação da sociedade nas fases de criação e gestão das Unidades de Conservação e a possibilidade de, no futuro, outras novas categorias serem criadas em todas as esferas de governo.

16. Este assunto pode ser visto em mais detalhes em MERCADANTE (2000), GUILLAUMON (2000), e MEDEIROS (2003). 


\title{
RODRIGO MEDEIROS
}

\section{EVOLUÇÃO DAS TIPOLOGIAS E CATEGORIAS DE ÁREAS PROTEGIDAS NO BRASIL}

\section{Resumo}

As áreas protegidas são importante instrumento de conservação dos recursos naturais. Elas começaram a ser territorialmente demarcadas no Brasil nos anos 30 e, desde então, passaram por longo processo de amadurecimento que levou à criação de distintas tipologias e categorias. Este trabalho visa analisar a evolução dessas áreas no Brasil, buscando compreender sua lógica de criação e a inserção nos principais contextos políticos nacionais e internacionais. Discutem-se ainda aspectos relativos à gestão do sistema atual.

ambiental

Palavras-chave: áreas protegidas - unidades de conservação - política

\section{EVOLUTION OF TYPOLOGIES AND CATEGORIES OF PROTECTED AREAS IN BRAZIL}

\begin{abstract}
Protected areas are an important instrument for the conservation of natural resources. They were firstly demarcated in Brazil in the 1930s and, since then, they went through a long process of evolution resulting in the creation of a series of distinct typologies and categories of protected areas. The present study aims to analyze the evolution of these categories of protected areas in Brazil, in order to evaluate the logic behind their creation as well as their insertion in the main national and international political contexts. Aspects related to the management of the actual system are also herein discussed.
\end{abstract}

Keywords: Protected Areas - Conservation Unities - environmental policy 